\title{
The Impacts of Low-Level Laser Therapy - A Complementary Treatment in the Management of Side Effects After Implant Surgery
}

\author{
Roya Safdari ${ }^{1}$, Narges Pouremadi ${ }^{1}$, Ehsan Talebzadeh ${ }^{2 *}$, Arash Mottaghi ${ }^{3}$, Shahram Amini ${ }^{4}$, Abolfath \\ Hossienzadeh², Bijan Movahedian Attar ${ }^{5}$ \\ 'Islamic Azad University, Isfahan (Khorasgan) Branch, Isfahan, Iran \\ ${ }^{2}$ Department of Oral and Maxillofacial Surgery, School of Dentistry, Islamic Azad University, Isfahan (Khorasgan) Branch, \\ Isfahan, Iran \\ ${ }^{3}$ Department of Oral Diseases, School of Dentistry, Islamic Azad University, Isfahan (Khorasgan) Branch, Isfahan, Iran \\ ${ }^{4}$ Department of Periodontics, School of Dentistry, Islamic Azad University, Isfahan (Khorasgan) Branch, Isfahan, Iran \\ ${ }^{5}$ Dental Implant Research and Department of Oral and Maxillofacial Surgery, School of Dentistry, Isfahan University of \\ Medical Science, Isfahan, Iran
}

\section{*Correspondence to \\ Ehsan Talebzadeh, Department of Oral and Maxillofacial Surgery, \\ Dental School, Islamic Azad \\ University, Isfahan (Khorasgan) \\ Branch, Isfahan, Iran. \\ Tel: +98 9131085058; \\ Fax: +984133363231 \\ Email: \\ Ehsantalebzadeh11@gmail.com}

Published online 28 July 2018

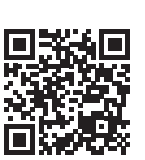

\begin{abstract}
Introduction: One of the most important medical applications of laser is low-level laser therapy (LLLT). In this method, laser radiation penetrates easily into the target tissue. The aim of this study was to investigate whether LLLT can reduce the side effects of advanced implant surgery. Methods: In this triple-blind clinical trial, 30 patients aged 25 to 65 years were selected for implant insertion and divided into two groups. In the laser group, immediately after the surgery, 72 hours and 1 week after the surgery, the surgical site was irradiated with an $830 \mathrm{~nm}$ laser. The dose required for the laser therapy was $5 \mathrm{~J} / \mathrm{cm}^{2}$. The degree of pain, facial swelling and wound healing were analyzed using statistical methods.

Results: Our results showed that at 12, 24, 48, and 72 hours after the surgery, the pain level was reduced in the laser group compared with the placebo group $(P<0.05)$. Swelling of the face was also significantly reduced 7 days after surgery in the laser group $(P<0.05)$. The investigation on the recovery conditions of the surgical site showed that on the $3 \mathrm{rd}, 7$ th and 14 th days after the surgery, higher levels of wound healing have been achieved $(P<0.05)$.

Conclusion: Our results suggest that laser, as a complementary therapy; can be used to reduce the severity and duration of pain. Also, laser can reduce facial swelling and accelerate wound healing.

Keywords: Low-level laser therapy; Sinus lift; Wound healing; Side effects; Implant failure.
\end{abstract}

\section{Introduction}

Implant therapy has undesirable side effects. The most common side effects include tooth loosening of the teeth adjacent to the implant, bleeding, pain, swelling, ecchymosis, paresthesia, nerve damage, and implant failure. $^{1-3}$ Prevention of inflammation after surgery is critical in order to reduce pain, swelling, and infection. ${ }^{4}$ One of the most important laser applications is in medical sciences, in which laser works based on the interaction between laser photons and tissues. ${ }^{5,6}$ This interaction depends on physical parameters such as laser power, laser wavelength and optical properties of the target tissue. ${ }^{7,8}$ In low-level laser therapy (LLLT), which works based on photochemical interactions in cells or photobiostimulation, the laser irradiation easily penetrates into the target tissue due to the low power output of the laser, the selected wavelength of the laser beams being between $630-1300 \mathrm{~nm}$, and other specific characteristics of the laser beams called coherence. ${ }^{9-12}$ Previous studies have shown that LLLT can be effective to accelerate healing and pain relief through reduction of mediators and inflammatory cells and increased endorphin, respectively. ${ }^{13}$ This modality is acceptable and cost-effective. ${ }^{13,14}$ Many dentists use identical drugs for different treatments and there is no agreement to prescribe the drugs based on the patient's health status. ${ }^{15,16}$ The aim of this study was to investigate the effect of LLLT using $830 \mathrm{~nm}$ wavelength and $120 \mathrm{~mW}$ power in the management of the side effects of implant surgery.
Methods
Population
In this triple-blind clinical trial (in which the subject, the person administering treatment, and the person 
evaluating the response to treatment were blinded to treatment allocation) a total of 30 patients aged 18-30 years, seeking bone grafting or sinus lift at the same session were selected for implant therapy and divided into two groups (laser and control groups). Sampling was done by simple random sampling. All patients were selected from the School of Dentistry, Azad University of Isfahan Iran, from February 2014 to May 2015. The Cochran method was used to calculate the sample volume. A consent form was signed by the patients and they were selected according to the following inclusion criteria: Patients older than 18 years and with a healthy oral mucosa, without systemic diseases, and volunteering for implant surgery. Moreover, patients with implant failure, pregnancy, light sensitivity, diabetes, prescribed antibiotics or corticosteroids in the past two weeks, smokers, and alcohol drinkers were excluded. Age, sex, jaw surgery and the type of surgery were matched.

\section{Study Technique}

After giving the written informed consent, surgery was done and the patients were guided to a room with standard conditions for laser and given protective glasses (goggles). Diode laser was used in this study with an $830 \mathrm{~nm}$ wavelength (Twin Laser MMOptics, Sao Carlos, Germany). This study needed continuous radiations. So, acylation wire (yellow wire) was connected to DC wire (red wire) with $33 \mathrm{k} \Omega$. A key was embedded for switching the circuit on or off (Figure 1) while Sanaye Optic Iran (SA IRAN CO) confirmed the wavelength and output power of the mounted device. In the laser groups, the implant surgery area was irritated in the buccal and lingual aspects separately (Figure 2). Laser parameters

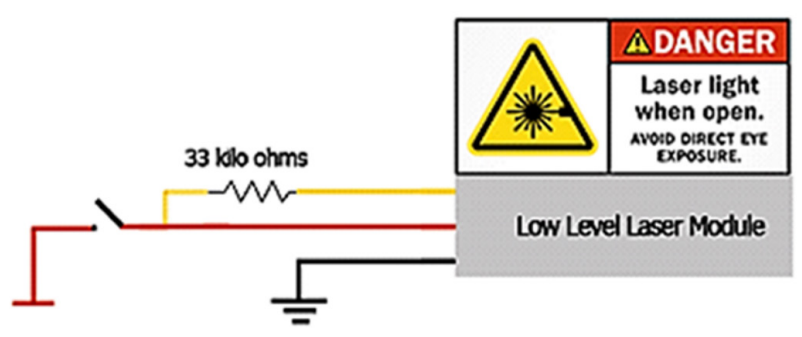

Figure 1. Laser Circuit.

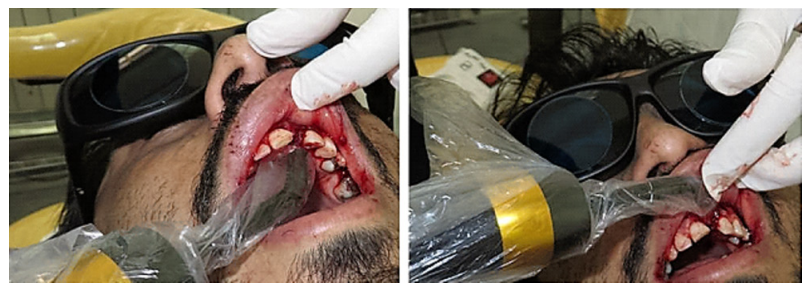

Figure 2. Radiation at the Site of Surgical Implants, Buccal (Right) And Lingual (Left) Separately. were $830 \mathrm{~nm}$ wavelength, $12 \mathrm{~mW}$ power with $5 \mathrm{~J} / \mathrm{cm}^{2}$ energy. Exposure time was calculated for 8 seconds based on energy formula (with laser protective glasses). Common medications given to the patients after the implant surgery were as follows:

For all patients, amoxicillin $500 \mathrm{mg}$ and metronidazole $250 \mathrm{mg}$ every 8 hours were prescribed for 7 days.

- Analgesics were recommended for patients experiencing pain in the early weeks.

- Dexamethasone $8 \mathrm{mg}$ single dose IM was used immediately after the surgery for all patients.

- Ice packs for extra-oral and surgical sites were used alternatively for 20 minutes and this procedure was repeated within 24 to 36 hours after surgery.

- Chemical plaque was controlled by chlorhexidine $(12 / 0 \%)$ for a period of 2 weeks. One week and 3 days after surgery $5 \mathrm{j} / \mathrm{cm}^{2}$ energy was radiated to this area again. This procedure was also performed for all members of the control group in the same way and at the same time (but the laser was not activated). The degree of pain was recorded after 12, 24, 48 and 72 hours based on visual analogue scale [VAS] from zero (no pain) to 10 (at death). Also, the type and number of analgesics consumed by the patients were recorded; facial swelling was recorded by using linear measurements 3 and 7 days after surgery (Figure 3). Determination of the degree of wound healing was performed on days 3, 7 and 14 after surgery as follows: 0 for complete wound healing, 1 for wound healing and the presence of a thin line of fibrin layer, 2 for wound healing and the presence of fibrin, 3 for incomplete wound closure and dehiscence, and 4 for wounds that were not closed and were necrotic (Figure 4).

\section{Statistical Analysis}

SPSS software (Statistical Package for Social Science, version 21.0, SPSS Inc., Chicago, IL, USA) was used for data analysis. $T$ test was used in order to compare the duration and severity of pain, consumption of analgesics and facial swelling rate between 2 groups (control and laser). Chisquare test was used for matching between 2 groups. Also, Mann-Whitney test was used for comparison of wound healing between laser and control groups.

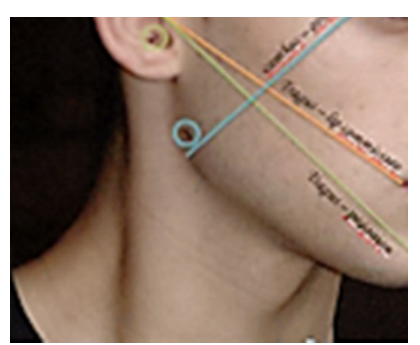

Figure 3. Clinical Approach to Measuring Swelling of Face: 1tragus to the corner of the mouth, 2- tragus to Pogonion 3-outer corner of the eye to gonium. 


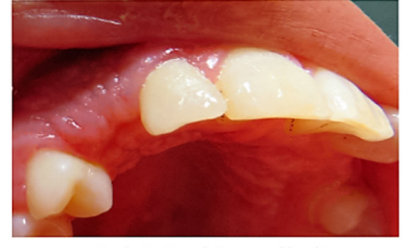

Grade 0: Complete wound healing
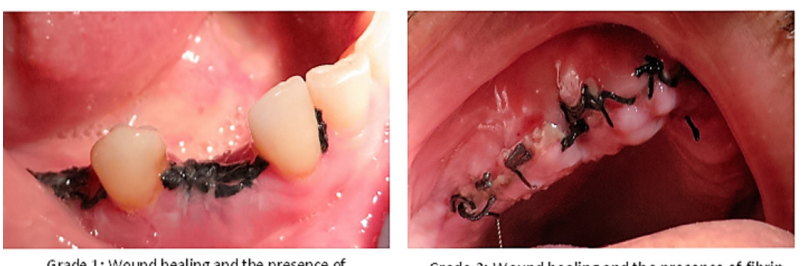
a thin line of fibrin layer


Grade 3: Incomplete wound closure (Dehiscen

Grade 4: Wounds that are not closed (Necrosis)

Figure 4. The Degree of Wound Healing Clinically.

\section{Results}

This study was carried out on 30 eligible patients in two groups of laser treatment and placebo groups. The age and sex of the patients in this study were matched and with no significant difference between the two groups $(P>0.05)$. The frequency of surgical site (jaw irradiated) was calculated, and in accordance with the chi-square test, there was no significant difference between the 2 groups $(P=0.37)$. Also, the frequency of the surgery type had no significant difference between the 2 groups $(P=0.9)$.

$T$ test showed that the degree of pain (showed with VAS) significantly reduced at 12 hours $(P<0.001), 24$ hours $(P<0.001), 48$ hours $(P=0.004)$ and 72 hours $(P=0.04)$ after surgery in the laser group compared with placebo (Table 1).

The average duration of painless time in the two groups was calculated and shown in Table 2. In the laser group, the pain disappeared faster than in the control group. $T$ test showed that consumption of analgesics in the two groups had no significant differences $(P=0.62)$. Also, the facial early index (as a baseline to check facial swelling) had no significant differences between the two groups. Facial swelling was measured at 72 hours and one week after surgery (Table 3). 72 hours after surgery the swelling of the face (Figure 3) did not differ significantly between the two groups $(P=0.09)$ but was significantly reduced 1 week after surgery in the laser group $(P=0.003)$.

Surgery recovery area on days 3, 7 and 14 after surgery in both groups is shown in Table 4. Mann-Whitney test showed that wound healing (area of operation) on the third day after surgery was significant between the 2 groups $(P=0.01)$ that means the laser group had a better response for wound healing. Also, this index was significant on the seventh day after surgery $(P=0.04)$ and 14 days after surgery $(P=0.02)$.

\section{Discussion}

Side effects are an inevitable part of therapies in medicine. Edema, trismus, pain, and infections are the most common side effects of implant therapy. A relatively new strategy to control the side effects is the use of LLLT. ${ }^{1,17}$

Previous studies have shown that LLLT can be effective to accelerate healing and pain relief through reduction of inflammatory mediators and cells and increase the amount of endorphin, respectively. ${ }^{18}$ The results of this study showed that laser therapy is an effective method for reducing the severity and duration of pain, reducing facial swelling and accelerating wound healing in many tissues. However, our results are similar to studies that LLLT have been used for third molar surgery. ${ }^{19,20}$ In this study, we observed a decrease in pain intensity at 12,24 , 48,72 hours after surgery in the laser group compared with the placebo group. Also, the results of this study indicated that laser treatment can reduce the duration of pain in the laser group compared with the placebo group. The effects of LLLT for pain relief include reduced nerve conduction velocity, action potential reduction,

Table 2. The Average Duration of Painless, Consumption of Analgesics in 2 Groups

\begin{tabular}{lccccc}
\hline \multirow{2}{*}{ Variables } & \multicolumn{2}{c}{ Placebo } & \multicolumn{2}{c}{ Laser } & \multirow{2}{*}{$\boldsymbol{P}$ Value } \\
\cline { 2 - 5 } & Mean & SD & Mean & SD & \\
\hline Duration of painless & 57.2 & 5.93 & 24.8 & 7.12 & $<0.001$ \\
Consumption analgesics & 5 & 1.22 & 4.33 & 0.91 & 0.62 \\
\hline
\end{tabular}

Table 3. The Average Primary Facial Index, Value of Swelling in Third and Seventh Days After Surgery in 2 Groups

\begin{tabular}{lcccccc}
\hline \multirow{2}{*}{ Variables } & \multicolumn{3}{c}{ Placebo } & \multicolumn{2}{c}{ Laser } & \multirow{2}{*}{$\boldsymbol{P}$ Value } \\
\cline { 2 - 5 } & Mean & SD & Mean & SD & \\
\hline Primary Facial Index & 36.1 & 2.2 & 36.05 & 2.7 & 0.92 \\
Value of swelling in 3rd day & 1.2 & 0.6 & 0.8 & 0.5 & 0.09 \\
Value of swelling in 7th day & 0.53 & 0.1 & 0.15 & 0.05 & 0.003 \\
\hline
\end{tabular}

Table 1. The Mean VAS at Different Times in the 2 Groups

\begin{tabular}{|c|c|c|c|c|c|c|c|c|}
\hline \multirow{2}{*}{ Groups } & \multicolumn{2}{|c|}{ After $12 \mathrm{~h}$} & \multicolumn{2}{|c|}{ After $24 \mathrm{~h}$} & \multicolumn{2}{|c|}{ After $48 \mathrm{~h}$} & \multicolumn{2}{|c|}{ After $72 \mathrm{~h}$} \\
\hline & Mean & SD & Mean & SD & Mean & SD & Mean & SD \\
\hline Placebo & 4.5 & 2.53 & 2.53 & 1.59 & 2.2 & 0.75 & 0.8 & 1.42 \\
\hline Laser & 1.14 & 0.36 & 0.46 & 0.25 & 0.26 & 0.15 & 0.13 & 0.09 \\
\hline$P$ value & \multicolumn{2}{|c|}{$<0.001$} & \multicolumn{2}{|c|}{$<0.001$} & \multicolumn{2}{|c|}{0.004} & \multicolumn{2}{|c|}{0.04} \\
\hline
\end{tabular}


Table 4. Distribution of the Status of Wound Healing at Different Times in 2 Groups

\begin{tabular}{|c|c|c|c|c|c|c|c|c|c|c|c|}
\hline \multirow{2}{*}{ Wound Healing Status } & \multicolumn{2}{|c|}{ Complete Wound Healing } & \multicolumn{2}{|c|}{ Grade 1} & \multicolumn{2}{|c|}{ Grade 2} & \multicolumn{2}{|c|}{ Grade 3} & \multicolumn{2}{|c|}{ Grade 4} & \multirow[t]{2}{*}{$P$ Value } \\
\hline & Placebo & Laser & Placebo & Laser & Placebo & Laser & Placebo & Laser & Placebo & Laser & \\
\hline 3rd Day & 0 & 0 & 0 & 20 & 46.7 & 66.7 & 46.7 & 13.3 & 6.7 & 0 & 0.01 \\
\hline 7th Day & 0 & 6.7 & 26.7 & 53.3 & 46.7 & 33.3 & 20 & 6.7 & 6.7 & 0 & 0.04 \\
\hline 14th Day & 13.3 & 46.7 & 33.3 & 33.3 & 46.7 & 20 & 6.7 & 0 & 0 & 0 & 0.02 \\
\hline
\end{tabular}

and selective inhibition of $\mathrm{A} \delta$ and $\mathrm{C}$ fibers and reduced painful stimuli. ${ }^{21}$

Positive effects of LLLT in pain reduction are frequently reported. ${ }^{22-24}$ However, some other studies have declared that despite a minor decrease in pain, LLLT had no other effect between laser and control groups. ${ }^{25,26}$ Therefore, an overall comparison of postoperative complications including pain is very difficult. The reasons for this difficulty can be attributed to different wavelengths of laser, a large variety of laser parameters, differences in experimental studies, sample size and study days. Laser can reduce the swelling through vasodilatation, increased circulation, lymphatic drainage, phagocytosis, and changes in the synthesis of prostaglandins. ${ }^{22,27}$ Consistent with these findings, our results show that in the laser group, a significant reduction was seen in swelling of the face on the seventh day after surgery compared with the placebo group.

The results of the present study showed a significantly higher degree of recovery in the laser group compared with the placebo group on 3, 7 and 14 days after the surgery. These results are consistent with data from in vivo and in vitro studies which showed that LLLT facilitated mobility of fibroblasts and keratinocytes, collagen synthesis, angiogenesis, and release of growth factors. ${ }^{28}$ They also confirm the results of studies of other researchers who demonstrated that the use of LLLT can accelerate wound healing after gingivectomy. ${ }^{28,29}$ One of the limitations of this project was the small size of the sample, and further studies with larger sample sizes may be useful in support of these claims.

\section{Conclusion}

Despite the common use of lasers in surgery, little knowledge exists in relation to other types of lasers, including low-level lasers. Due to the wide variety of laser variables, so far optimal parameters have not been set for these purposes. One of the most important medical applications of laser is LLLT in which the laser radiation penetrates easily into the target tissue. Our results suggest that laser, as a complementary therapy; can be used to reduce the severity and duration of pain. Also, laser can reduce facial swelling and accelerate wound healing.

\section{Conflict of Interests}

The authors declare no conflict of interest.

\section{Ethical Considerations}

Our study protocol was approved by the Local Ethics Committee of Research and Clinical Center for Azad University, Isfahan, Iran.

\section{Acknowledgments}

This work was supported by the Dental Faculty of Islamic Azad University in Isfahan (Khorasgan Branch), Isfahan, Iran. The authors are thankful to all dental members of the Dental Faculty in Islamic Azad University, staffs as well as clinics and private offices in Isfahan for providing the necessary facilities for the preparation of this study.

\section{References}

1. Camargo IB, Van Sickels JE. Surgical complications after implant placement. Dent Clin North Am. 2015;59(1):57-72. doi:10.1016/j.cden.2014.08.003

2. Froum SJ. Dental Implant Complications: Etiology, Prevention, and Treatment. John Wiley \& Sons; 2015.

3. Misch CE, Resnik RR. Medical Evaluation of the Dental Implant. 4th ed. Elsevier, Contemporary Implant Dentistry; 2007:421.

4. Poeschl PW, Eckel D, Poeschl E. Postoperative prophylactic antibiotic treatment in third molar surgery--a necessity? J Oral Maxillofac Surg. 2004;62(1):3-8.

5. Niemz MH. Laser-Tissue Interactions: Fundamentals and Applications. 2nd ed. Springer Science \& Business Media; 2013.

6. Hillenkamp F. Lasers in biology and medicine. Springer Science \& Business Media; 2013.

7. Reichelt J, Winter J, Meister J, Frentzen M, Kraus D. A novel blue light laser system for surgical applications in dentistry: evaluation of specific laser-tissue interactions in monolayer cultures. Clin Oral Investig. 2017;21(4):985-994. doi:10.1007/s00784-016-1864-6

8. Walsh LJ. The use of lasers in implantology: an overview. J Oral Implantol. 1992;18(4):335-340.

9. Lubart R, Eichler M, Lavi R, Friedman H, Shainberg A. Low-energy laser irradiation promotes cellular redox activity. Photomed Laser Surg. 2005;23(1):3-9. doi:10.1089/ pho.2005.23.3

10. Khadra M, Kasem N, Haanaes HR, Ellingsen JE, Lyngstadaas SP. Enhancement of bone formation in rat calvarial bone defects using low-level laser therapy. Oral Surg Oral Med Oral Pathol Oral Radiol Endod. 2004;97(6):693-700. doi:10.1016/s1079210403006851

11. Khadra M, Ronold HJ, Lyngstadaas SP, Ellingsen JE, Haanaes HR. Low-level laser therapy stimulates boneimplant interaction: an experimental study in rabbits. Clin Oral Implants Res. 2004;15(3):325-332. doi:10.1111/j.1600- 
0501.2004.00994.X

12. Rashidi S, Yadollahpour A, Mirzaiyan M. Low Level Laser Therapy for the Treatment of Chronic Wound: Clinical Considerations. Biomed Pharmacol J. 2015;8(2):1121-7. doi:10.13005/bpj/866

13. Bjordal JM, Johnson MI, Iversen V, Aimbire F, LopesMartins RA. Low-level laser therapy in acute pain: a systematic review of possible mechanisms of action and clinical effects in randomized placebo-controlled trials. Photomed Laser Surg. 2006;24(2):158-168. doi:10.1089/ pho.2006.24.158

14. Ferreira DM, Zangaro RA, Villaverde AB, et al. Analgesic effect of He-Ne $(632.8 \mathrm{~nm})$ low-level laser therapy on acute inflammatory pain. Photomed Laser Surg. 2005;23(2):177181. doi:10.1089/pho.2005.23.177

15. Misch CE. Contemporary Implant Dentistry. Elsevier Health Sciences; 2007.

16. Misch CE, Dietsh F. Bone-grafting materials in implant dentistry. Implant Dent. 1993;2(3):158-167.

17. Chow RT, Johnson MI, Lopes-Martins RA, Bjordal JM. Efficacy of low-level laser therapy in the management of neck pain: a systematic review and meta-analysis of randomised placebo or active-treatment controlled trials. Lancet. 2009;374(9705):1897-1908. doi:10.1016/s01406736(09)61522-1

18. Fekrazad R, Chiniforush N, Bouraima SA, et al. Low Level Laser Therapy in Management of Complications after Intra Oral Surgeries. J Lasers Med Sci. 2012. 2012;3(4):6. doi:10.22037/2010.v3i4.3543

19. Hagiwara S, Iwasaka H, Okuda K, Noguchi T. GaAlAs $(830 \mathrm{~nm})$ low-level laser enhances peripheral endogenous opioid analgesia in rats. Lasers Surg Med. 2007;39(10):797802. doi:10.1002/lsm.20583

20. Basford JR. Low intensity laser therapy: still not an established clinical tool. Lasers Surg Med. 1995;16(4):331342.

21. Parker S, Convissar RA. Principles and Practice of Laser Dentistry. St. Louis: Mosby Elsevier; 2011.
22. Merigo E, Vescovi P, Margalit M, et al. Efficacy of LLLT in swelling and pain control after the extraction of lower impacted third molars. Laser Ther. 2015;24(1):39-46. doi:10.5978/islsm.15-OR-05

23. Kazancioglu HO, Ezirganli S, Demirtas N. Comparison of the influence of ozone and laser therapies on pain, swelling, and trismus following impacted third-molar surgery. Lasers Med Sci. 2014;29(4):1313-1319. doi:10.1007/s10103013-1300-y

24. Markovic AB, Todorovic L. Postoperative analgesia after lower third molar surgery: contribution of the use of longacting local anesthetics, low-power laser, and diclofenac. Oral Surg Oral Med Oral Pathol Oral Radiol Endod. 2006;102(5):e4-8. doi:10.1016/j.tripleo.2006.02.024

25. Ferrante M, Petrini M, Trentini P, Perfetti G, Spoto G. Effect of low-level laser therapy after extraction of impacted lower third molars. Lasers Med Sci. 2013;28(3):845-849. doi:10.1007/s10103-012-1174-4

26. Paschoal MA, Santos-Pinto L. Therapeutic effects of lowlevel laser therapy after premolar extraction in adolescents: a randomized double-blind clinical trial. Photomed Laser Surg. 2012;30(9):559-564. doi:10.1089/pho.2012.3243

27. Aras MH, Gungormus M. Placebo-controlled randomized clinical trial of the effect two different low-level laser therapies (LLLT)--intraoral and extraoral--on trismus and facial swelling following surgical extraction of the lower third molar. Lasers Med Sci. 2010;25(5):641-645. doi:10.1007/s10103-009-0684-1

28. Ozcelik O, Cenk Haytac M, Kunin A, Seydaoglu G. Improved wound healing by low-level laser irradiation after gingivectomy operations: a controlled clinical pilot study. J Clin Periodontol. 2008;35(3):250-254. doi:10.1111/ j.1600-051X.2007.01194.x

29. Martu S, Amalinei C, Tatarciuc M, et al. Healing process and laser therapy in the superficial periodontium: a histological study. Rom J Morphol Embryol. 2012;53(1):111-116. 